\title{
A Study of the Gas-Phase Reaction Between Protonated Acetaldehyde and Methanol
}

\author{
Gregory G. Dolnikowski, ${ }^{\S}$ Timothy G. Heath, ${ }^{\S}$ and J. Throck Watson ${ }^{\dagger \S}$ \\ Departments of Biochemistry ${ }^{\dagger}$ and Chemistry ${ }^{\$}$, Michigan State University, East Lansing, Michigan, USA
}

\author{
James H. Scrivens \\ ICI Chemicals and Polymers Group, Middlesbrough, Cleveland, United Kingdom
}

\author{
Christian H. Rolando \\ Laboratoire de Chimie, Ecole Normale Supérieure, Paris, France
}

\begin{abstract}
Protonated acetaldehyde is methylated on the oxygen during interaction with methanol in the gas phase. The ionic product of the ion'molecule reaction between methanol and protonated acetaldehyde is identical with C-protonated methylvinyl ether (high-pressure ionization), and with the $\left(\mathrm{M}-\mathrm{C}_{2} \mathrm{H}_{5}\right)^{+}$fragment ion of sec-butyl methyl ether (following electron ionization), and also with the $\left(\mathrm{M}-\mathrm{OCH}_{3}\right)^{+}$fragment ion of acetaldehyde dimethylacetal (following electron ionization). The structures of these ions and the mechanism of their formation were established by isotope-labeling experiments and collision-induced dissociation mass spectra of model compounds obtained with three different types of tandem mass spectrometers (BEQQ, triple-quadrupole, and a penta-quadrupole instrument). Gas phase synthesis of the product ion from $\left[{ }^{2} \mathrm{H}_{3}\right]$-methanol or $\left[{ }^{2} \mathrm{H}_{4}\right]$-acetaldehyde provided insight into its mode of formation and collision-induced dissociation. (J Am Soc Mass Spectrom 1990, 1, 481-488)
\end{abstract}

$\mathrm{I}$ nvestigations of ion/molecule reactions of methanol, beyond those used in providing "soft" ionization, have revealed a rich chemistry in reactions with aliphatic acids and esters [1-3]. In our studies of the ion/molecule reactions in mixtures of methanol and acetaldehyde we pursued the question of whether C-alkylation $[4,5]$ or the anticipated O-alkylation $[6-10]$ was involved in the formation of the covalently-bonded product ions. This article describes the use of three different tandem mass spectrometry (MS/MS) techniques combined with collision-induced dissociation (CID) to elucidate the structure of methylated acetaldehyde ions formed by gas-phase ion/molecule reactions of protonated acetaldehyde with methanol.

\section{Experimental}

A VG ZAB HSQ hybrid tandem mass spectrometer (VG Instruments, Inc., Manchester, England) of BEQQ design [11] was used for performing most of the high pressure ion/molecule reactions. All of the collision-induced dissociation (CID) daughter ion mass spectra acquired from this instrument were performed at $91-\mathrm{eV}$ collision energy and at approximately $3 \times$

Address reprint requests to J. Throck Watson, Department of Bio chemistry, Michigan State University, East Lansing, MI 48824.

-Present address: USDA Human Nutrition Research Center on Aging at Tufts Universily, 711 Washington St., Boston, MA 02111.

$10^{-3}$ torr of argon; these collision conditions optimized fragmentation over the mass range under investigation. All samples were introduced via conventional gas line connections or heated inlet systems.

The low pressure ion/molecule reaction studies involving deuterium-labeled reagents were perfurmed on a prototype Nermag (Delsi-Nermag Instr., Argenteuil, France) tandem penta-quadrupole mass spectrometer [12]. Briefly, the Nermag instrument consists of an electron ionization/chemical ionization (EI/CI) ion source, a mass-selective quadrupole $\left(Q_{1}\right)$, a collision cell $\left(Q_{2}\right)$ comprised of an rf-only quadrupole, a second mass-selective quadrupole $\left(Q_{3}\right)$, followed by a second collision cell $\left(Q_{4}\right)$ comprised of two rf-only quadrupoles that can be electrically biased to each other, a third mass-selective quadrupole $\left(Q_{5}\right)$, and an electron multiplier detector. Routine operation of the instrument permits ions produced during ion/molecule reactions in $Q_{2}$ to be analyzed by CID in $Q_{4}$. This instrument is also equipped with a microprocessorcontrolled module that permits ions to be confined in $\mathrm{Q}_{2}$ for variable periods of time [13]. When used, a typical confinement period is $0.5 \mathrm{~ms}$, which is approximately an order of magnitude longer than the average residence time for an ion being transmitted through the cell. The typical collision energy for obtaining CID daughter ion mass spectra is $25 \mathrm{eV}$ at a pressure of $3 \times 10^{-3}$ torr argon (measured in situ with a Baratron (MKS Instruments, Inc., Andover, 
MA) gauge). All samples were introduced into a reservoir that was connected to the ion source via a valve with a variable leak.

The Finnigan TSQ-70 (Finnigan-MAT, San Jose, CA) triple-quadrupole mass spectrometer (TQMS) was equipped with a Varian (Varian Assoc., Walnut Creek, CA) 3400 gas chromatograph. The ion source was maintained at $150^{\circ} \mathrm{C}$; the ionizing current was $200 \mu \mathrm{A}$ at $70 \mathrm{eV}$. Ion/molecule reactions between molecules and ions of methanol and acetaldehyde in the ion source were conducted by introducing two microliters of both compounds (neat) through the gas liquid chromatographic (GLC) inlet, thereby providing transitory high pressure conditions as the two compounds coeluted into the CI-volume (without CI gas). Protonated molecules of acetone, allyl alcohol, and methylvinyl ether were prepared by "self $\mathrm{CI}^{\prime}$ in the $\mathrm{CI}$ volume without conventional $\mathrm{CI}$ gas. Acetaldehyde dimethylacetal and diethyl ether were introduced into an EI volume. One micruliter volumes of neat acetone, allyl alcohol, and acetaldehyde dimethylacetal were introduced separately through the GLC inlet; methylvinyl ether (a gas under standard conditions) was introduced through a fixed gas reservoir via a controlled leak. Diethyl ether was introduced into a reservoir that was connected to the ion source via a valve with a variable leak. In all cases the parent ion of mass 59 was selected by $Q_{1}$ for CID in the rf-only $\mathrm{Q}_{2}$ collision cell, with argon at $10^{-4}$ torr. The CID daughter ion mass spectra were collected with $25-\mathrm{eV}$ collision energy $\left(E_{1 a b}\right)$. None of the three instruments permitted direct measurement of the pressure in the high pressure source, so these pressures were estimated by reference to remote ionization gauge readings.

All chemicals were research grade and were used as acquired from commercial sources without further purification. Methanol, acetaldehyde, and acetaldehyde dimethylacetal were purchased from Mallinckrodt, Inc. (St. Louis, MO); acetone, allyl alcohol, and propionaldehyde were obtained from Fisher Scientific Co. (Fairlawn, NI); and diethyl ether was purchased from EM Science (Gibbstown, NJ). ${ }^{18} \mathrm{O}$-methanol (> 95\% enrichment) was acquired from Icon Services Inc. (Summit, NJ). Deuterium-labeled methanol and acetaldehyde were purchased from Sigma Chemical Co. (St. Louis, MO). Methylvinyl ether was purchased from Aldrich Chemical Co. (Milwaukee, WI).

\section{Results and Discussion}

Ion/molecule reactions in a high pressure (approximately 0.1 torr) ionization chamber containing methanol and acetaldehyde produce a reaction product mass spectrum characterized by predominant peaks (as shown in Figure 1) representing protonated methanol $(\mathrm{m} / \mathrm{z} 33)$, protonated acetaldehyde $(\mathrm{m} / \mathrm{z} 45)$, protonated dimer species of methanol and acetaldehyde ( $m / z 65$ and $m / z 89$, respectively), protonated

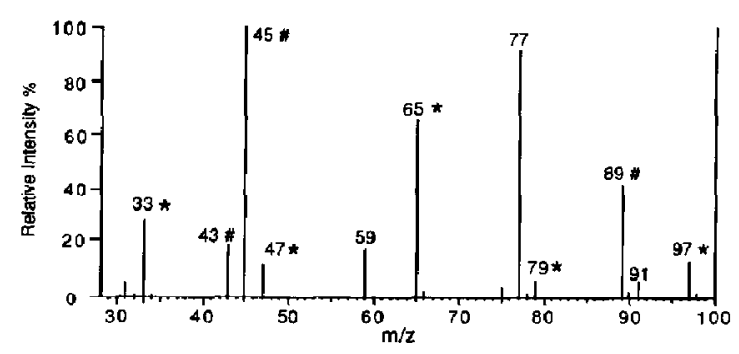

A.

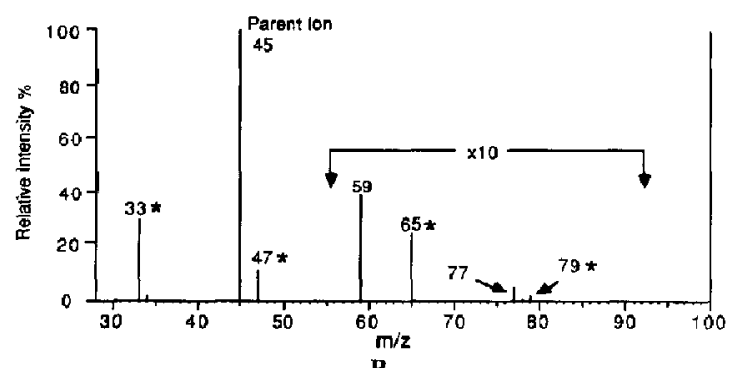

B

Figure 1. (a) Reaction product spectrum of ions produced during ion/molecule reactions following EI of methanol and acetaldehyde in a high pressure ion source of the TQMS. Those peaks marked by an asterisk represent known product ions of methanol self-Cl. Those peaks marked with a pound represent known product ions of acetaldehyde self-CI. (b) Reaction product spectrum of ions produced during ion/molecule reactions of protonated acetaldehyde with methanol in the center quadrupole of a TQMS. Methanol pressure was $2 \times 10^{-3}$ torr and collision energy was $1 \mathrm{eV}$. Those peaks marked by an asterisk represent known product ions of the ion/molecule reaction between protonated methanol (generated by proton transfer in this case) and methanol.

dimethyl ether resulting from O-methylation of methanol ( $m / z 47)[9,14,15]$, and by significant peaks representing acetaldehyde plus $15 \mathrm{u}(\mathrm{m} / \mathrm{z} 59)$ and acetaldehyde plus $33 \mathrm{u}(\mathrm{m} / \mathrm{z} 77)$. The peak at $m / z 77$ represents the intermediate in the reaction of protonated acetaldehyde and methanol, and the peak at $m / z 59$ represents methylated acetaldehyde. The structures of the ions represented by peaks at $m / z 59$ and $m / z 77$ were investigated using gas-phase syntheses with deuterium-labeled reagents ${ }_{I}{ }^{8}$ O-labeled reagents, and CID experiments.

The reaction product mass spectrum shown in Figure $1 \mathrm{~b}$ was obtained when protonated acetaldehyde at low kinetic energy reacted with methanol in the collision cell of the TQMS at a pressure of 2 mtorr. Product ion peaks at $\mathrm{m} / z 59$ and $\mathrm{m} / \mathrm{z} 77$ are observed along with those for reaction products that may be attributed to proton transfer to methanol; other peaks represent product ions from subsequent ion/molecule reactions in methanol $[14,15]$. The product ion peaks marked by an asterisk in Figure 1 are expected during reactions of methanol with methanol ions in a high pressure ion source. It is interesting to note that in contrast to the above reaction, when protonated 
methanol is reacted with acetaldehyde in the TQMS, no peaks at $m / z 59$ and $m / z 77$ are observed for reaction products. Apparently, the reactive intermediate (shown eventually in Scheme III) can be formed only when the proton is on acetaldehyde. In other experiments with protonated methanol and acetaldehyde in the penta-quadrupole instrument, the product ion of mass 59 was observed, but only when ion confunement was used [13]. Considering the differences in proton affinity (PA) of methanol and acetaldehyde (PA methanol $=761.0 \mathrm{~kJ} / \mathrm{mole}$, $\mathrm{PA}$ acetaldehyde $=780.8 \mathrm{~kJ} /$ mole), there is proton exchange to form protonated acetaldehyde, which then reacts with trace levels of methanol that leak into the collision cell from the ion source; only with ion confinement in the penta-quadrupole instrument was the reaction time long enough to generate a discernible concentration of product ions from reaction of protonated acetaldehyde with the trace levels of methanol. Another possibility could involve formation of a proton bound complex in the collision cell from the protonated methanol from the ion source and the acetaldehyde in the collision cell; appropriate transfer of the proton within the complex could be sufficiently slow [15] that the covalently bonded species is formed only after an extended period, as is available with ion trapping.

The structure of the ion/molecule reaction product ( $m / z 59$ ) was characterized by CID. The CID daughter ion mass spectrum of the $[\mathrm{M}+15]^{+}$ion $(m / z 59)$ formed under high pressure ion/molecule reaction conditions in the ion source of the BEQQ is shown in Figure 2a. The abundance of the parent ion, $[M+$ $15]^{+}$, is off scale (as is common in most BEQQ daughter spectra) and the spectrum is normalized to the most abundant daughter ion.

The CID daughter ion mass spectra of several isomeric ions of mass 59 were obtained with the BEQQ in a comparative effort to identify the structure of the product ion of mass 59 from the ion/molecule reaction of methanol with protonated acetaldehyde. Isomeric $\mathrm{C}_{3} \mathrm{H}_{7} \mathrm{O}^{+}$ion structures have been extensively investigated [16-23]. If thermochemistry were the determining factor in the formation of the $\mathrm{C}_{3} \mathrm{H}_{7} \mathrm{O}^{+}$product ion structure, then a variety of candidate structures must be considered (Scheme I). A composite of low energy CID daughter ion mass spectra of the protonated forms of acetone, methylvinyl ether, allyl alcohol, and propionaldehyde is shown in Figure $2 b-e$. Each of these isomers of mass 59 produces a different CID mass spectrum, none of which is identical with that of the ion/molecule reaction product ion in Figure $2 a$.

The BEQQ-CID daughter ion mass spectrum of the ion of mass 59 generated by $\alpha$-cleavage fragmentation of 2-methoxybutane [16] (also called sec-butyl methyl ether) following ionization by EI is shown in Figure 2f. All of the major peaks in Figure $2 f$ have relative intensities that fall within statistical variation of those

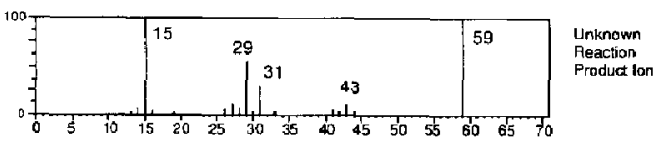

A
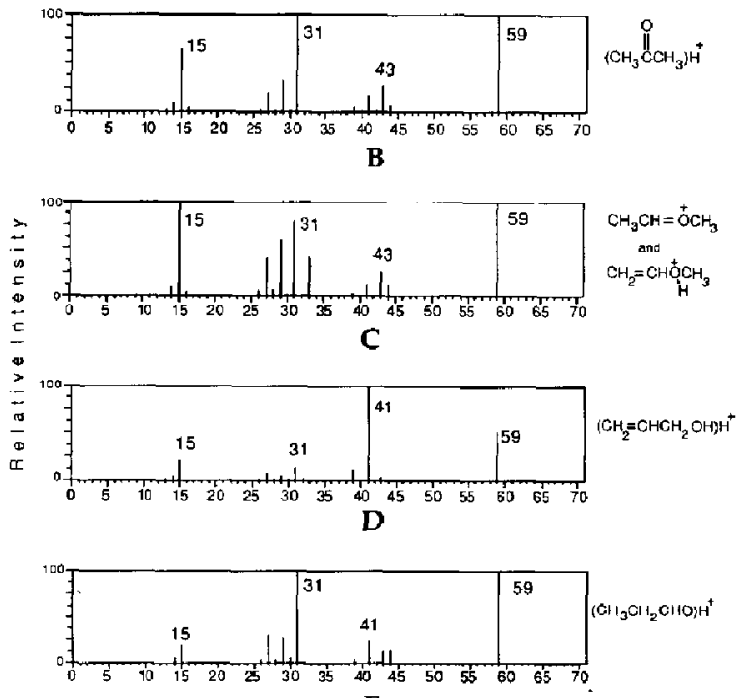

E

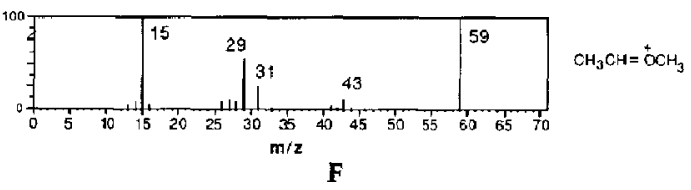

Figure 2. CID daughter ion mass spectrum (BEQQ) of: (a) ionic product ( $\mathrm{m} / \mathrm{z} 59$ ) from ion/molecule reactions conducted in a high pressure ion source containing methanol and acetaldehyde (parent ion peak at miz 59 is off scale); (b) protonated acetone ( $\mathrm{m} / \mathrm{z} 59$ off scale); (c) protonated methylvinyl ether ( $\mathrm{m} / \mathrm{z}$ 59 off scale); (d) protonated allyl alcohol; (e) protonated propionaldehyde ( $m / z 59$ off scale); and (f) ion of mass 59 formed by homolytic cleavage in the molecular ion of 2-methoxybutane following EI ( $m / z 59$ is off scale).

in Figure 2a. The agreement between the BEQQ-CID daughter ion mass spectra in Figure $2 \mathrm{a}$ and $\mathrm{f}$ indicates that the methylated acetaldehyde formed by ion/ molecule reaction in the gas phase has the same structure as the fragment ion of mass 59 formed by homolytic cleavage in the molecular ion of 2-methoxybutane following EI [16]. These data provide direct evidence that acetaldehyde is methylated on the oxygen during ion/molecule reactions in a high pressure ion source containing acetaldehyde and methanol.

A statistical evaluation of replicate CID spectra of protonated acetone obtained over a $36-h$ period, during which other BEQQ spectra reported herein were acquired, indicated that peak intensities at $m / z 15,27$, 29 , and 41 fluctuated with relative standard deviations (RSD) in the range of $3 \%$ to $11 \%$, while the peak intensity at $m / z 43 \mathrm{had}$ an RSD of $21 \%$. These data (not shown) demonstrate that the reproducibility of the low-energy $\mathrm{CID}$ technique is sufficient for the 


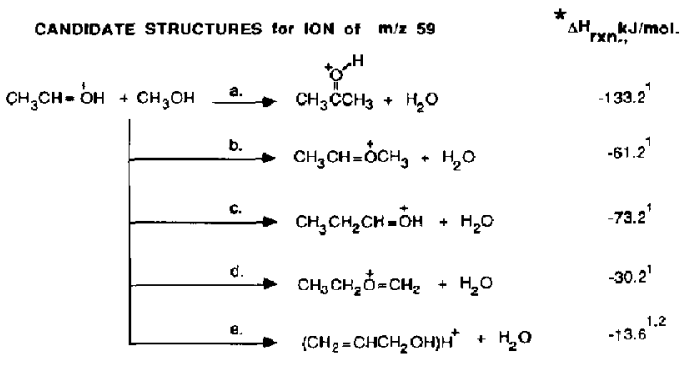

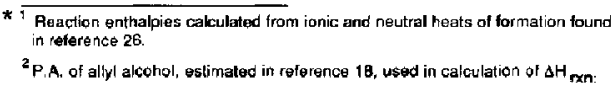

Scheme I

purpose of distinguishing the set of isomers represented by the CID spectra in Figure 2.

Additional confirmatory evidence for O-methylation was obtained from experiments conducted with the Nermag tandem penta-quadrupole mass spectrometer, which permitted gas-phase synthesis and subsequent CID of two different deuterium-labeled variants of the methylated acetaldehyde. Figure $3 a$ is the CID mass spectrum of $\mathrm{CH}_{3}-\mathrm{O}^{+}=\mathrm{CH}-\mathrm{CH}_{3}$ (synthesized in the gas phase from $\mathrm{CH}_{3} \mathrm{OH}_{2}^{+}$and $\mathrm{CH}_{3} \mathrm{CHO}$ ); Figure $3 \mathrm{~b}$ is the $\mathrm{CID}$ spectrum of $\mathrm{CD}_{3}-\mathrm{O}^{+}=\mathrm{CH}-\mathrm{CH}_{3}$ (synthesized in the gas phase from $\mathrm{CD}_{3} \mathrm{OD}_{2}^{+}$and $\mathrm{CH}_{3} \mathrm{CHO}$ ); and $3 \mathrm{c}$ is the $\mathrm{CID}$ spectrum of $\mathrm{CH}_{3}-\mathrm{O}^{+}=\mathrm{CD}-\mathrm{CD}_{3}$ (synthesized from $\mathrm{CH}_{3} \mathrm{OH}_{2}^{+}$and $\mathrm{CD}_{3} \mathrm{CDO}$ ). Scheme II summarizes the rationalized fragmentation pathways for each of the
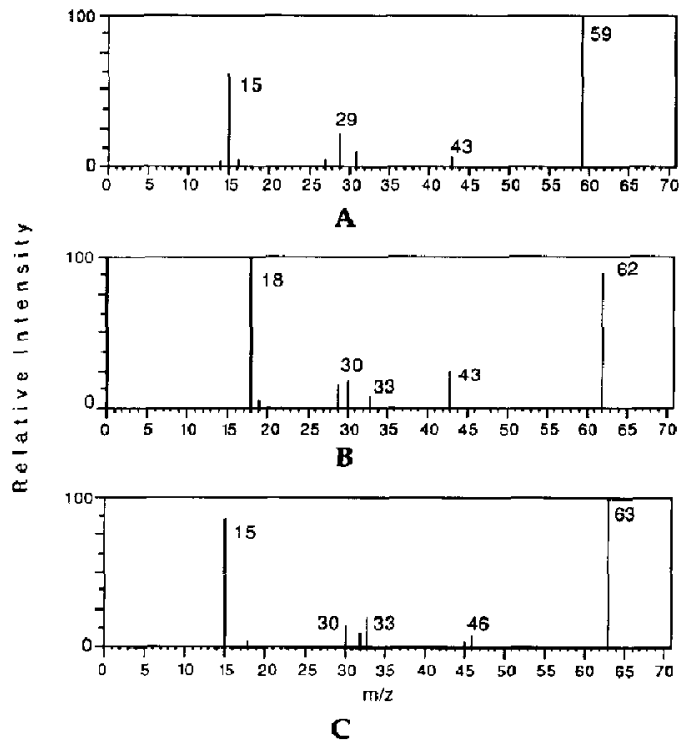

Figure 3. CID mass spectra (in $\mathrm{Q}_{4}$ of the penta-quadrupole) of isotopically labeled variants of methylated acetaldehyde synthesized in $\mathrm{Q}_{2}$ of the penta-quadrupole as follows: (a) CID of the $\left.{ }^{2} \mathrm{H}_{\mathrm{a}}\right]$-product ion of mass 59 (synthesized from $\mathrm{CH}_{3} \mathrm{OH}_{2}^{+}$and $\mathrm{CH}_{3} \mathrm{CHO}$ ). (b) $\mathrm{CID}$ of the $\left[{ }^{2} \mathrm{H}_{3}\right]$-product ion of mass 62 (synthesized from $\mathrm{CD}_{3} \mathrm{OD}_{2}^{+}$and $\mathrm{CH}_{3} \mathrm{CHO}$ ). (c) CID of the $\left[^{2} \mathrm{H}_{4}\right.$ l-product ion of mass 63 (synthesized from $\mathrm{CH}_{3} \mathrm{OH}_{2}^{+}$and $\mathrm{CD}_{3} \mathrm{CDO}$ ). three isotopic variants of methylated acetaldehyde. The daughter ions anticipated in Scheme II are represented by peaks in the CID mass spectra shown in Figure 3.

The triple quadrupole CID daughter ion mass spectra in Figure 4 also corroborate the results from the BEQQ instrument. Figure $4 a$ is the CID daughter ion mass spectrum of the reaction product ion of mass 59 formed when methanol and acetaldehyde are introduced into the $\mathrm{CI}$ ion source at high pressure (without reagent gas). Figure $4 \mathrm{~b}$ is the CID daughter ion mass spectrum of protonated methylvinyl ether produced by "self $\mathrm{Cl}^{\text {" }}$ of methylvinyl ether in a high pressure inn source. This spectrum does not match that in Figure $4 a$, just as that from the BEQQ in Figure $2 c$ does not match that in $2 a$. However, when the pressure of methylvinyl ether is increased by an order of magnitude, one obtains the CID daughter ion mass spectrum of protonated methylvinyl ether shown in Figure $4 c$, which agrees well with the CID daughter ion mass spectrum of methylated acetaldehyde in 4a. At the higher pressure conditions there are sufficient collisions to drive the protonation reaction to the thermodynamically favored $[24,25] \quad C$-protonated product; at lower pressures a mixture of $\mathrm{O}$-protonated (kinetically favored) and C-protonated species is produced. Thus, Figure $4 \mathrm{~b}$ represents the composite CID mass spectra of a mixture of O-protonated and C-protonated species, which explains why it does not match the CID mass spectrum of methylated acetaldehyde in 4a. Figure $4 \mathrm{~d}$ and $4 \mathrm{e}$ are the $\mathrm{CID}$ daughter ion mass spectra of protonated acetone and allyl alcohol, respectively, and $4 f$ is the CID daughter ion mass spectrum of the $\alpha$-cleavage fragment ion of diethyl ether. Clearly, none of these spectra matches that in Figure $4 a$. Figure $4 \mathrm{~g}$ is the CID daughter ion mass spectrum of the fragment ion of mass 59 formed by homolytic cleavage in the molecular ion of acetaldehyde dimethylacetal following ionization by EI. The CID daughter ion mass spectra in Figure $4 \mathrm{c}$ and $g$ match that in a, which supports the premise that the product ion of mass 59 from the reaction of protonated acetaldehyde and methanol has the structure illustrated in Schemes II and III.

It is interesting to compare some results obtained from the penta-quadrupole instrument with those obtained from the BEQQ and TQMS. Figure $2 a$ is the 91-eV CID daughter ion mass spectrum of methylated acetaldehyde produced under high pressure ionization conditions in the ion source of the BEQQ. Figure $3 a$ is the 25-eV CID daughter ion mass spectrum of methylated acetaldehyde produced by ion/molecule reactions at approximately $10^{-3}$ torr in the first quadrupole reaction chamber $\left(Q_{2}\right)$ of the pentaquadrupole instrument. Figure $4 a$ is the $25 \mathrm{eV} \mathrm{CID}$ mass spectrum of methylated acetaldehyde produced in a high pressure ion source in the TSQ-70. The CID daughter ion mass spectra in Figures $2 a, 3 a$, and $4 a$ agree quite well considering the substantial differ- 

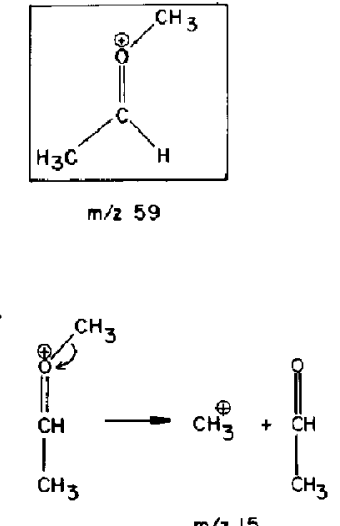

2.

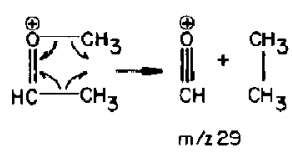

3.

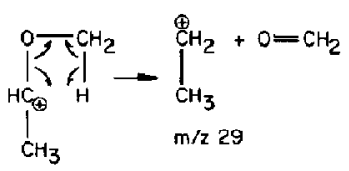

4.

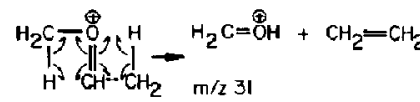
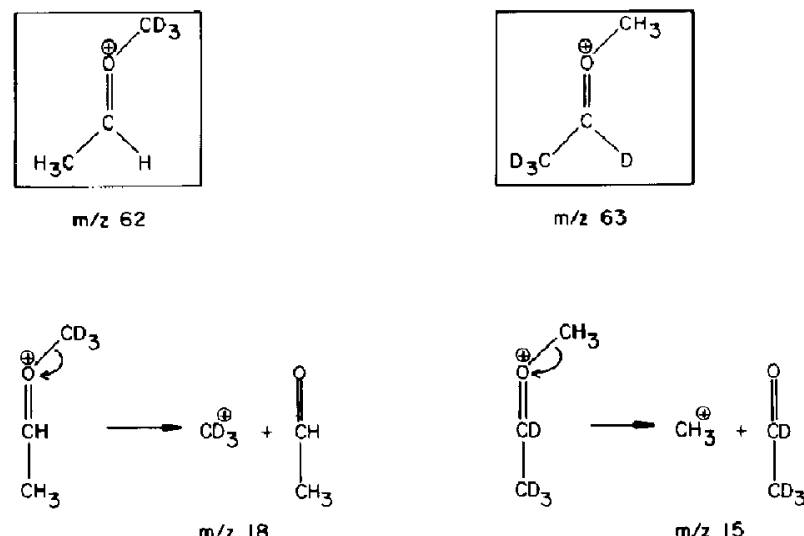

$\mathrm{m} / 215$

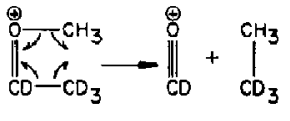

$\mathrm{m} / \mathrm{z} 30$

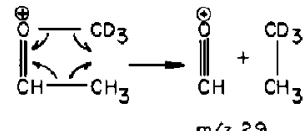

$\mathrm{m} / \mathrm{z} 29$

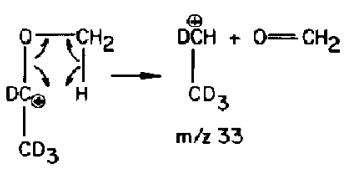

5.<smiles>CC(=O)C1CCCC1C</smiles><smiles>CC(=O)C1C2CCC1(C)O2</smiles>

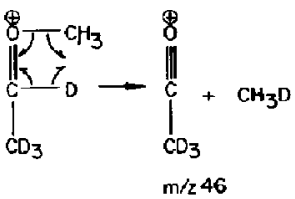

Scheme II

ences in conditions under which both the parent ion and daughter ions were formed.

Having established the identity of the ion of mass 59 , we wished to determine the mechanism or mechanisms for its production in the high pressure ion source and to determine the structure of the interme- diates (proposed in Scheme III). We postulate that there are two structures for the ion of mass 77 , each formed at thermal energies in either the ion source or in the quadrupole reaction chamber. These two structures differ in the locus of the charge in protonated acetaldehyde. Starting with the O-charged form of 


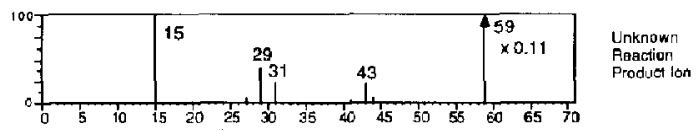

A
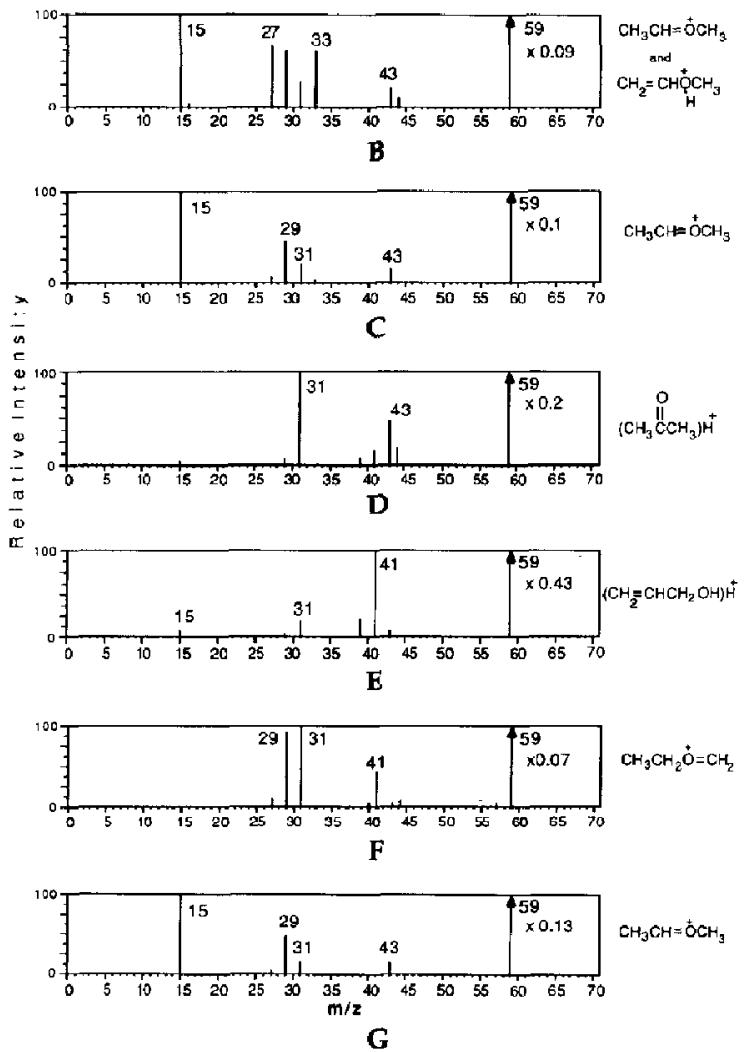

Figure 4. Daughter ion mass spectra obtained during CID in $Q_{2}$ of the TQMS of a parent ion of mass 59 corresponding to: (a) product ion from high pressure ion source containing methanol and acetaldehyde; (b) protonated methylvinyl ether (self-CI at lower pressure); (c) protonated methylvinyl ether (self-CI at higher pressure); (d) protonated acetone; (e) protonated allyl alcohol; $(f)$ fragment ion from diethyl ether following EI; and (B) fragment ion from acetaldehyde dimethylacetal following EI.

acetaldehyde, the proton becomes "sandwiched" between the oxygens of the acetaldehyde and the methanol (as shown at the left of Scheme III). Upon CID, this proton-bound "sandwich" form of the intermediate falls apart into either protonated methanol or protonated acetaldehyde (as shown in pathway (i) in Scheme III). With the C-charged form of protonated acetaldehyde, the intermediate involves close contact of the oxygen of methanol with the positively charged carbon in protonated acetaldehyde due to electrostatic forces, and also close contact between the oxygen of protonated acetaldehyde and the methyl carbon of methanol (as shown in the middle of Scheme III at the top). This "close encounter" form of the intermediate permits covalent bond formation (as indicated in the middle of Scheme III), thereby produc- ing a protonated molecular species of mass 77 . Further, we postulate that the protonated molecular species of mass 77 decomposes promptly by elimination of methanol to form an ion of mass 45 , or rapidly undergoes hydrogen transfer (as indicated at the right of Scheme III) and abruptly eliminates water to form an ion of mass 59 (as shown in pathway (iii). The CID daughter ion mass spectrum of $m / z 77$ (Figure 5a) supports the validity of Scheme III by showing that during low eV collisions with argon, some of the ions of mass 77 expel water to form a daughter ion of mass 59. However, at collision energies above $5 \mathrm{eV}$, no peak is observed at $m / z 59$. This examination of the energetics of CID indirectly supports the postulate made above for two different structural forms of the intermediate. The "close encounter" adduct has electrostatic forces holding only two of the four critical atoms together; with collisions at energies in excess of $5 \mathrm{eV}\left(\mathrm{E}_{\text {lab }}\right)$, proper alignment of the other two atoms is interrupted before covalent bond formation can be accomplished.

The majority of the ions of mass 77 are in the traditional proton-bound "sandwich" adduct of methanol and acetaldehyde (upper left in Scheme III) as the dominant CID daughter ions are protonated methanol $(\mathrm{m} / \mathrm{z} 33)$ or protonated acetaldehyde $(\mathrm{m} / \mathrm{z}$ 45), respectively (see pathway (i) of Scheme III). With the introduction of ${ }^{18} \mathrm{O}$-methanol, both intermediates shift to mass 79 . The CID daughter ion mass spectrum of mass 79 , shown in Figure $5 b$, indicates that the

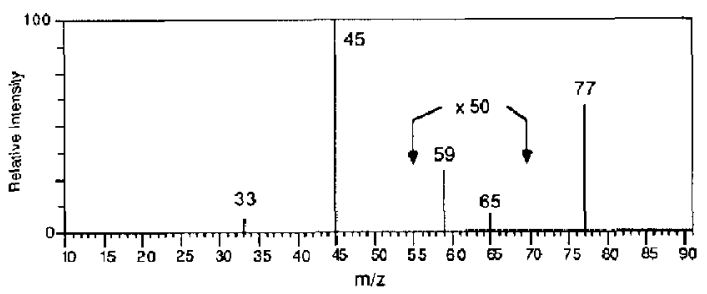

A

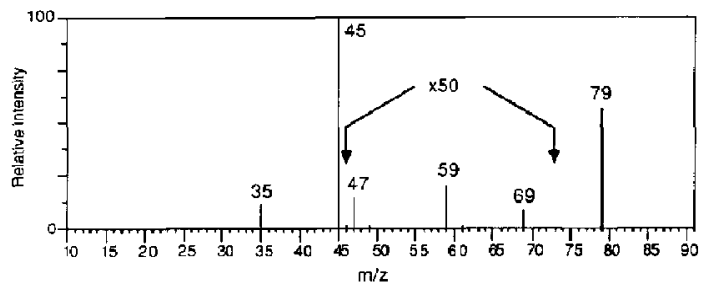

B

Figure 5. (a) $\mathrm{CID}\left(\mathrm{E}_{\mathrm{lab}}=4 \mathrm{eV}\right)$ daughter ion mass spectrum of the adduct ion of mass 77 formed by ion/molecule reactions occurring after methanol and acetaldehyde were placed in the high pressure ion source of the TQMS. (b) $\operatorname{CID}\left(\mathrm{E}_{\text {lab }}=4 \mathrm{eV}\right)$ daughter ion mass spectrum of the adduct ion of mass 79 formed by ion/molecule reactions occurring after $\mathrm{CH}_{3}{ }^{18} \mathrm{OH}$ and acetaldehyde were placed in the high pressure ion source of the TQMS. The CID daughter mass of $m / 277$ or $m / z 79\left(\mathrm{CH}_{3}{ }^{18} \mathrm{OH}\right)$ spectra obtained above $5 \mathrm{eV}$ showed no peak at $m / 2$ 59. Putative structures are shown in Scheme III. 


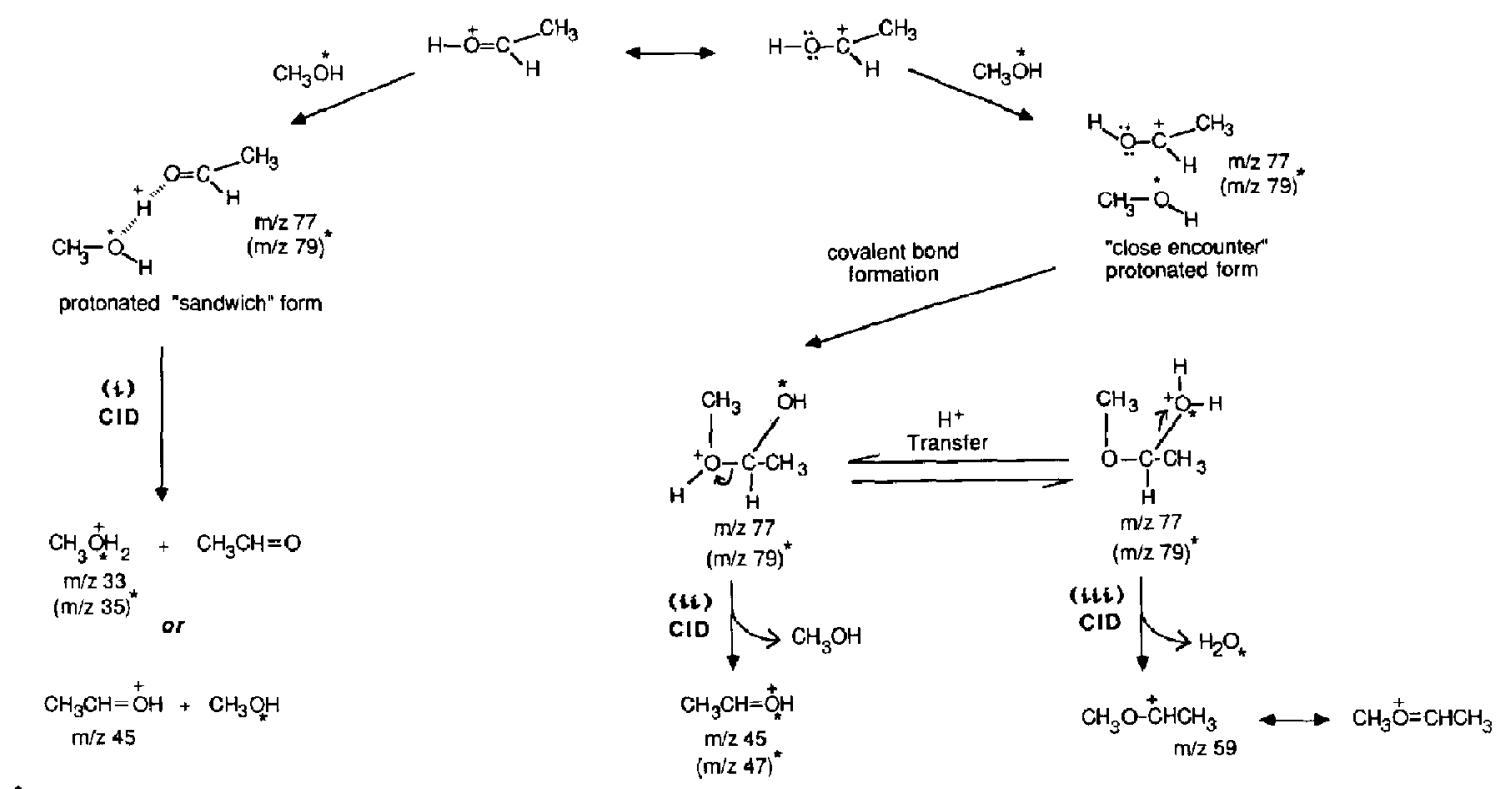

* indicates site of ${ }^{18} \mathrm{O}$ and corrosponding $\mathrm{m} / \mathrm{z}$ value in parentheses

\section{Scheme III}

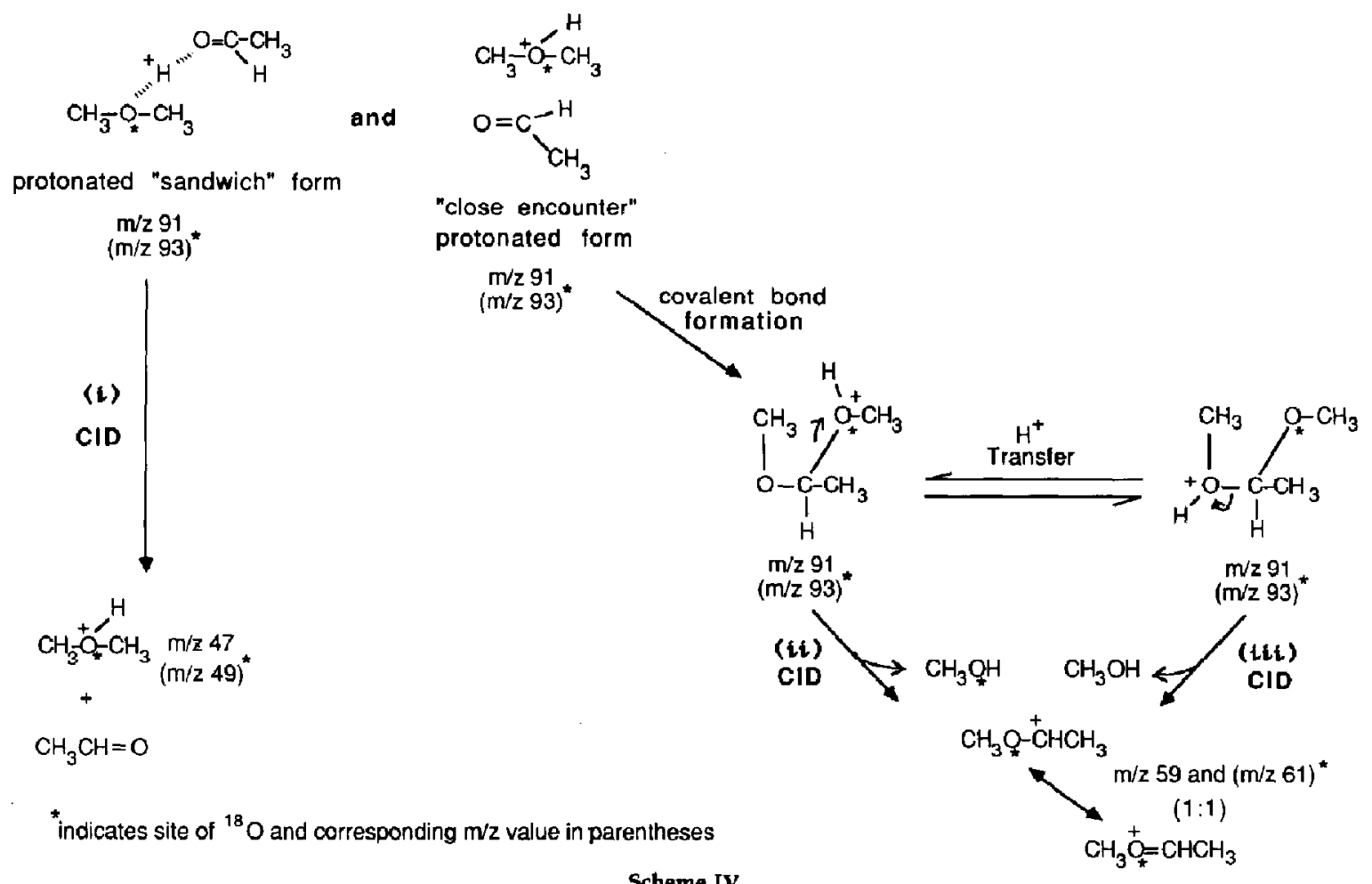

Scheme IV

collision complex intermediate loses $\mathrm{CH}_{3} \mathrm{OH}$ to give a peak at $\mathrm{m} / \mathrm{z} 47$ representing protonated ${ }^{18} \mathrm{O}$-acetaldehyde (this corroborates pathway (ii) of Scheme III) and providing evidence for nascent covalent bonds. The "sandwich" form of the intermediate made from
$\mathrm{CH}_{3}{ }^{18} \mathrm{OH}$ still generates a daughter ion of mass 45 upon $\mathrm{CID}$ as demonstrated in Figure $5 \mathrm{~b}$. After hydrogen transfer, the collision complex intermediate also loses $\mathrm{H}_{2}^{18} \mathrm{O}$ upon $\mathrm{CID}$ to give the reaction product at mass 59 (this corroborates pathway (iii) of Scheme 
III). The intensity of these fragment ion peaks at $\mathrm{m} / \mathrm{z}$ 59 and $\mathrm{m} / \mathrm{z} 47$ are observed in a $4: 3$ ratio. The peak at $m / z 65$ (in Figure 5a) appears to represent a protonbound dimer of methanol due to leakage of methanol from the source into the collision cell because this peak shifts to $\mathrm{m} / \mathrm{z} 69$ when ${ }^{18} \mathrm{O}$-methanol is admitted to the ion source with acetaldehyde (Figure $5 b$ ). We postulate that a molecular beam of methanol dimers $[27,28]$ from the ion source enters the collision cell where it captures a proton from the intermediate of mass 77 to form a protonated dimer of methanol.

A parent ion scan of $\mathrm{m} / \mathrm{z} 59$ was obtained (not shown) to determine if there were other intermediates that might account for the formation of the product at $m / z 59$. The results indicated that $m / z 59$ arises not only from an intermediate at $m / z 77$, but also from an intermediate at $\mathrm{m} / \mathrm{z}$ 91; this second reaction sequence is illustrated in Scheme IV. An ion/molecule reaction product in methanol is protonated dimethyl ether [14, 15]. Protonated dimethyl ether reacts with acetaldehyde to give a collision complex at $m / z 91$, some of which represent a protonated acetaldehyde dimethyl acetal intermediate. The CID daughter ion mass spectrum of mass 91 at low-energy collisions with argon in the TQMS gives a daughter ion at $m / z 59$ (pathways (ii) or (iii) of Scheme IV). When ${ }^{18} \mathrm{O}$-methanol is introduced into the ion source, the peak for the intermediate shifts to $\mathrm{m} / \mathrm{z} 93$. Upon CID, this ion of mass 93 yields fragment ion peaks at $m / z 59$ and $\mathrm{m} / \mathrm{z} 61$ (in a 1:1 ratio), which correspond to loss of $\mathrm{CH}_{3}{ }^{18} \mathrm{OH}$ and $\mathrm{CH}_{3} \mathrm{OH}$, respectively, as would be expected statistically from the equivalent structures in equilibrium through proton transfer, as indicated in Scheme IV. When $\left[{ }^{2} \mathrm{H}_{4}\right]$-methanol is used, an adduct intermediate of mass 98 yields the product ion of mass 62 .

In summary, the results of this study provide direct evidence by CID mass spectrometry for O-alkylation in the gas-phase reaction between protonated acetaldehyde and methanol. Specifically, a major ionic product of this ion/molecule reaction has the same structure as C-protonated methylvinyl ether formed by self-CI. Collision-induced dissociation daughter ion mass spectra of a variety of isomeric ions of mass 59 as obtained by a triple-quadrupole instrument, a penta-quadrupole instrument, and a hybrid BEQQ instrument are described and compared. The CID daughter mass spectra of $C$-protonated methylvinyl ether produced by $\mathrm{CI}$ and of $\mathrm{CH}_{3}-\mathrm{O}^{+}=\mathrm{CH}-\mathrm{CH}_{3}$ produced by alpha cleavage in the fragmentation of either 2-methoxybutane [16] or acetaldehyde dimethylacetal under EI conditions are identical with the CID daughter mass spectrum of the ionic product from reaction of methanol with protonated acetaldehyde. Gas-phase syntheses of isotopically labeled alkylated ions from deuterium-labeled precursor ions or molecules provide data to rationalize fragmentation pathways during $\mathrm{CID}$. In addition, ${ }^{18} \mathrm{O}$-labeling experiments have produced data that reveal the mechanism of the $\mathrm{CH}_{3}-\mathrm{O}^{+}=\mathrm{CH}-\mathrm{CH}_{3}$ formation.

\section{Acknowledgments}

We thank Dr. Richard Bowen, University of Warwick, Professors John Stille and John Allison, Michigan State University, and Dr. Helene Mestdagh, Ecole Normale Supérieure, Paris, for helpful discussions. This work was supported in part by the Biomedical Research Technology Program (DRR-5-P41-00480-21) of NIH.

\section{References}

1. Tiedemann, P. W.; Riveros, J. M. I. Am. Chem. Soc, 1974, $96,185-189$.

2. Fomarini, S. J. Am. Chem. Soc. 1988, 110, 963-965.

3. Dolnikowski, G. G. Ph.D. Dissertation, Michigan State University, 1987.

4. Bouchoux, G.; Hoppilliard, Y.; Houriet, R. New J. Chem. $1987,11,225$

5. Audier, H. E.; Monteiro, C.; Robin, D. Org. Mass Spectrom. 1989, 24, 353.

6. Audier, H. E.; Berthomieu, D.; Hudhomme, P.; Monteiro, C.; Mourgues, P. Org. Mass Spectrom. 1990, 25, 87-88.

7. Morizur, J.-P.; Martigny, I.; Tortajada, J.; Geribaldi, S. Org. Mass Spectrom. 1990, 25, 89-91.

8. Wesdemiotis, C.; McLafferty, F. W. Tetrahedron 1981, 37, 3111-3113.

9. Wesdemiotis, C.; McLafferty, F. W. Org. Mass Spectrom. 1981, 16, 381-382.

10. Maquestiau, A.; Jortay, C.; Beugnies, D.; Flemmang, R.; Houriet, R.; Rolli, E.; Bouchoux, G. Int. J. Mass Spectrom. Ion Proc. 1988, 82, 33-46.

11. Louis, J. N.; Wright, L. G.; Cooks, R. G.; Schoen, A. E. Anal. Chem. 1985, 57, 2918.

12. Beaugrand, C.; Devant, G.; Rolando, C.: Jaouen, D. Presented at the 34th ASMS Conference on Mass Spectrometry and Allied Topics, Cincinnati, June 1986, pp. 220-221.

13. Beaugrand, C.; Jaouen, D.; Mestdagh, H.; Rolando, C. Attal. Chem. 1989, 61, 1447-1453.

14. Henis, J. M. S. J. Am. Chem. Soc. 1968, 90, 844-851.

15. Kleingeld, J. C.; Nibbering, N. M. M. Org. Mass Spectrom. $1982,17,136-139$

16. Hvistendahl, G.; Williams, D. H. J. Am. Chem. Soc. 1975, $97,3097$.

17. Bowen, R. D.; Harrison, A. G. Org. Mass Spertrom. 1981, 16, 159.

18. Boweth, R. D.; Williams, D. H.; Hvistendahl, G.; Kalman, J. R. Org. Mass Spectrom. 1978, 13, 721.

19. Hvistendahl, G.; Bowen, R. D.; Williams, D. H. J. Chem. Sac. Chem. Comm, 1976, 294.

20. Brodbelt-Lustig, J. S.; Cooks, R. G. Int. I. Mass Spectrom. Ion Proc. 1988, 86, 253.

21. McLafferty, F. W.; Sakai, I. Org. Mass Spectrom. 1973, 7, 971.

22. Wagner, W.; Heimbach, H.; Levsen, $\mathrm{K}$. Int. I. Mass Spectrom. Ion Phys. 1980, 36, 125.

23. Harrison, A. G.; Gäumann, T.; Stahl, D. Org. Mass Spectrom. 1983, 18, 517.

24. Nobes, R. H.; Radom, L. Org. Mass Spectrom. 1984, 19, 385.

25. Bouchoux, G.; Djazi, F.; Hoppilliard, Y.; Houriet, R.; Rolli, E. Org. Mass Spectrom. 1986, 21, 209-213.

26. Lias, S. G.; Bartmess, J. E.; Liebman, J. F.; Holmes, J. L.; Levin, R. D.; Mallard, W. G. J. Phys. Chem. Ref. Data, 17, Suppl. \# 1 1988.

27. Buck, U.; Gu, X.; Lauenstein, C.; Rudolph, A. J. Phys. Chem. 1988, 92, 5561-5562.

28. Morgan, S.; Castleman, A. W., Jr. I. Phỵs. Chem. 1989, 93, 4544-4550. 